\title{
Community-based psychiatry around the world
}

\author{
Амбулаторная психиатрия в мире \\ DOI: 10.17650/2712-7672-2020-1-1-47-48
}

\author{
Olga A. Karpenko O., Maya A. Kulygina, \\ George P. Kostyuk \\ Mental-health clinic No. 1 named after N.A. Alexeev, Moscow, \\ Russia
}

The $100^{\text {th }}$ anniversary of community-based psychiatry in Russia was commemorated in 2019. This event was celebrated within the framework of the international conference, "Centenary of Community-Based Psychiatry: Landmarks and Perspectives" which was held from $16^{\text {th }}$ to $18^{\text {th }}$ May, 2019 in Moscow; participants from 72 countries took part in the conference. Leading Russian and foreign psychiatrists in the field of community psychiatry exchanged findings and innovated solutions for their practice and for research purposes to improve the quality of psychiatric care for patients.

In Russia, the first community-based mental health services were developed in Moscow in 1919 by order of the healthcare department of the local government. In 1924 the first mental dispensary (specialized psychiatry setting for delivering primary mental healthcare) opened in Moscow [1, 2]. Since that time, Russian psychiatry has developed concurrently in both an institutional and community-based direction, acquiring rich clinical experience.

Over the last few decades, the importance of the development of community-based mental healthcare was highlighted in WHO documents [3]. Outpatient services are at the front-line of psychiatric care to provide detection, therapy and prevention of mental health disorders, as well as psychosocial rehabilitation on a long-term basis.

The community psychiatric service should comply with the local healthcare system, therefore, a uniform model for all countries does not exist. The organizational form and efficacy of such work depends on many factors, such as financing, governmental policy, legal rules, culture-related traditions, etc. A country-level approach to community psychiatric service development can be

\author{
Ольга А. Карпенко, Майя А. Кулыгина, \\ Георгий П. Костюк \\ Психиатрическая клиническая больница № 1 им. Н.А. \\ Алексеева, Москва, Россия
}

a source of new ideas and inspiration for better global mental healthcare.

It was for this reason that we decided to collect brief reviews from different countries all over the world, presenting their experiences and giving a panoramic view of community-based psychiatry. We developed a set of questions to make the reports comparable and to highlight the key milestones in the development of community-based psychiatric care.

The following list of questions was suggested for the authors" consideration:

\section{When was community-based mental healthcare established in your country?}

2. What are the general characteristics of communitybased mental healthcare in your country in relation to the following:

- where is it delivered (settings)?

- who can deliver it (what kind of specialists)?

- what kind of mental healthcare is provided and for whom?

- what are the connections between primary care units and community-based mental health services? - what are the connections between communitybased mental health services and other mental health services available in your country?

- what is the source of financing?

- what are the legal aspects?

3. What have been the general characteristics of the mental health system since the 1980s (preferably in numerical format) as follows:

- number of psychiatrists, psychotherapists, psychologists and other professionals involved 
in mental healthcare (per 100,000 of the population). - number of psychiatric beds (per 100,000 of the population), length of inpatient treatment, usual route followed by the patient after hospital discharge (medical referrals, organization of follow-up).

- mental healthcare facilities available in your country (mental hospitals, beds in general hospitals, day hospitals, outpatient offices, etc.).

4. What status does community-based mental healthcare have in the mental health and healthcare system in your country?

5. What are its strengths and weaknesses?

6. What plans are there for its future development? 7. Anything else that you consider to be important.

An invitation to write an article giving a description of the community-based psychiatry service was sent to the respected mental health professionals of more than 30 countries. The responses from all continents are still being collected. In the journal, we are starting to publish the reviews received by countries in every issue, in the 'special article' section.

\section{References}

1. Karpenko O, Kostyuk G. Community-based mental health services in Russia: past, present, and future. Lancet Psychiatry. 2018 Oct;5(10):778-780. doi: 10.1016/S2215-0366(18)30263-3. Epub 2018 Jul 30. PMID: 30072167.

2. Kostyuk GP, editor. Outpatient Mental Health Services in Moscow. History through today. M.: «KDU»; 2019. 268 p. doi: 10.31453/kdu. ru.91304.0035.

3. World Health Organization (WHO) [Internet]. The European mental health action plan 2013-2020. Geneva: World Health Organization, 2015. [cited 2020 Aug 15]. Available from: http:// www.euro.who.int/_data/assets/pdf_file/0020/280604/WHOEurope-Mental- Health-Acion-Plan-2013- 2020.pdf 